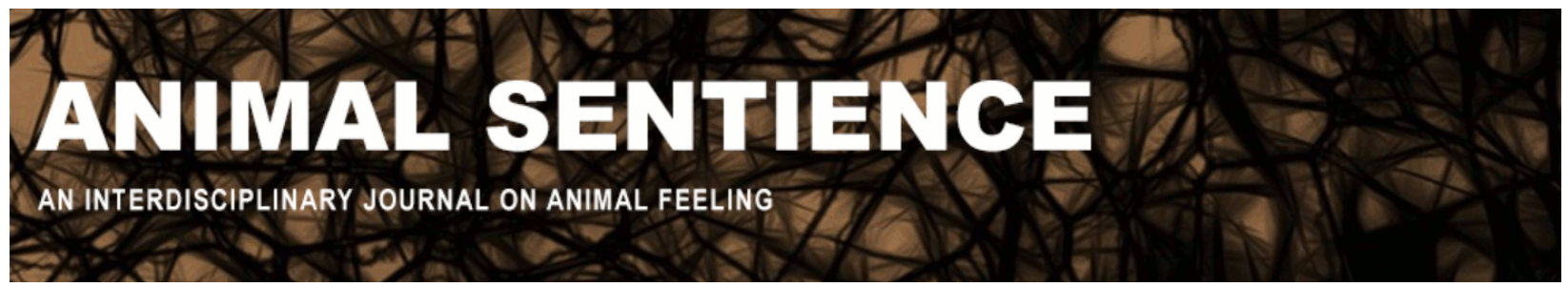

$\mathrm{Ng}$, Yew-Kwang (2016) How welfare biology and commonsense may help to reduce animal suffering. Animal Sentience 7(1)

DOI: $10.51291 / 2377-7478.1012$

Date of submission: 2015-04-16

Date of acceptance: 2015-12-11

(c) (†)

This article has appeared in the journal Animal

Sentience, a peer-reviewed journal on animal

cognition and feeling. It has been made open access,

free for all, by WellBeing International and deposited

in the WBI Studies Repository. For more information,

please contact

wbisr-info@wellbeingintl.org.

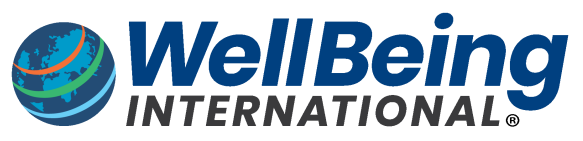

SOLUTIONS FOR PEOPLE, ANIMALS AND ENVIRONMENT 
$\mathrm{Ng}$, Yew-Kwang (2016) How welfare biology and commonsense may help to reduce animal suffering. Animal Sentience 7(1)

DOI: $10.51291 / 2377-7478.1012$

Date of submission: 2015-04-16

Date of acceptance: 2015-12-11

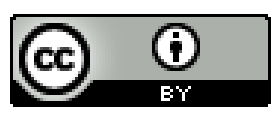

Cover Page Footnote

I am grateful to Dr. Timothy D. Hau of the University of Hong Kong for assistance. 
Call for Commentary: Animal Sentience publishes Open Peer Commentary on all accepted target articles. Target articles are peer-reviewed. Commentaries are editorially reviewed. There are submitted commentaries as well as invited commentaries. Commentaries appear as soon as they have been revised and accepted. Target article authors may respond to their commentaries individually or in a joint response to multiple commentaries.

Instructions: http://animalstudiesrepository.org/animsent/guidelines.html

\title{
How welfare biology and commonsense may help to reduce animal suffering
}

\author{
Yew-Kwang Ng \\ Division of Economics \\ Nanyang Technological University \\ Singapore
}

\begin{abstract}
Welfare biology is the study of the welfare of living things. Welfare is net happiness (enjoyment minus suffering). Since this necessarily involves feelings, Dawkins (2014) has suggested that animal welfare science may face a paradox, because feelings are very difficult to study. The following paper provides an explanation for how welfare biology could help to reduce this paradox by answering some difficult questions regarding animal welfare. Simple means based on commonsense could reduce animal suffering enormously at low or even negative costs to humans. Ways to increase the influence of animal welfare advocates are also discussed, focusing initially on farmed animals and restrictions that are not likely to impede scientific advances on which the future large improvements in animal welfare greatly depend.
\end{abstract}

Keywords: animal suffering, animal welfare, welfare biology, animal welfare science, animal sentience

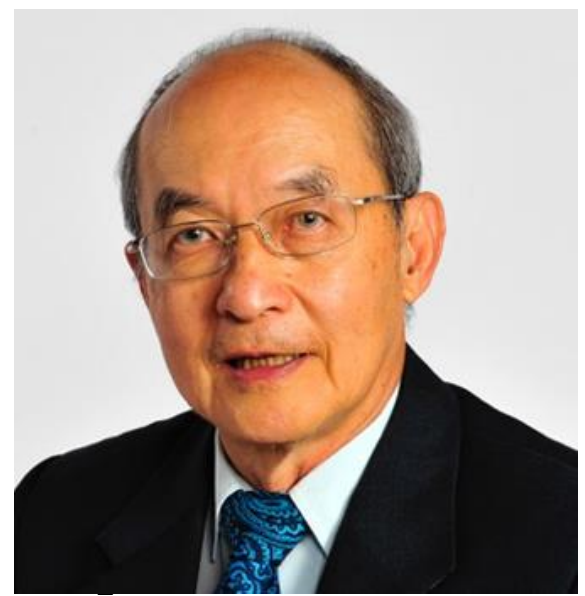

Yew-Kwang Ng ykng@ntu.edu.sg is Winsemius professor in economics at Nanyang Technological University. He is a fellow of the Academy of Social Sciences in Australia and Distinguished Fellow of the Economic Society of Australia. Yew-Kwang's recent books include: Common Mistakes in Economics by the Public, Students, Economists and Nobel Laureates (open access); and Happinessism.

Address: HSS-04-72, 14 Nanyang Drive, Singapore 637332 http://www.ntu.edu.sg/home/ykng/ 
It is encouraging to see very significant increases in interest in animal welfare in recent years and decades, including the large growth of scientific publications on animal welfare science (e.g., Walker et al., 2014). We should have had more compassion earlier and should have done more for animal welfare. However, better late than never. With the current increase in interest, if it is sustained, much more could be done. This paper attempts to show how welfare biology (which I helped to develop two decades ago; see Ng, 1995) could help. The hope is to make recommendations that will help resolve some difficult problems surrounding animal welfare (Carpendale, 2013/2016). There are some simple, commonsense methods that can help reduce animal suffering enormously at little cost - or even a net gain - to humans. Finally, how animal welfare advocates could increase their influence will be discussed.

\section{Welfare Biology vs. the World Knot}

Schopenhauer's (1906/2014) "world knot" refers to the philosophical problem of explaining consciousness: How could the material brain give rise to feeling? How could matter give rise to mind? This world knot is so difficult to unravel that it has lately been dubbed "the hard problem" (Chalmers, 1995). The philosopher Daniel Dennett's (1991) book is called Consciousness Explained, but having read the book from cover to cover and understood virtually everything in it, I still have not seen consciousness explained by even $0.01 \%$. In a very informative book (very highly recommended) reporting on many important recent findings in the neurosciences, Ramachandran (2012, p. 247) states that "Sometime in the twenty-first century, science will confront one of its last great mysteries: the nature of the self." I take this to mean the solution of the world knot. Ramachandran is apparently encouraged by important new findings to which he personally also contributed. Nevertheless, I do not believe the world knot will be unraveled even in the thirty-first century.

The difficulty of solving the hard problem is related to the difficulty of whether others, including animals, feel, that is, whether they are conscious (the "other-minds problem"). It is this empirical difficulty - together with an excessive concern about being accused of naïve anthropomorphism (especially by biologists), along with the century-long domination of Watson-Skinnerian behaviorism in psychology (though it had been waning in the last few decades) - that has made scientific research on the problem of animal welfare (and even just the recognition of the problem) so late in coming. The Cambridge Declaration on Animal Consciousness was adopted as late as July 7, 2012. As summarized in Wikipedia on Animal Welfare Science, "Although animal welfare has been of great concern for many thousands of years in religion and culture, the investigation of animal welfare using rigorous scientific methods is a relatively recent development. The world's first Professor of Animal Welfare Science, Donald Broom, was appointed by Cambridge University (UK) in 1986." The increasing interest in the last decade or so is hence much to be welcomed.

Although it is difficult to establish with certainty that any individual animal or species is capable of feeling and hence that their welfare is a matter of concern, this difficulty must not be over-emphasized. Strictly, this lack of $100 \%$ certainty applies also to members of our own species; the only exception is oneself, the subject of the only feelings 
anyone can ever feel: One may have $100 \%$ certainty that one feels what one feels while one is feeling it. This we already know from the outcome of Descartes's meditations on doubt and certainty: the Cogito. But in this philosophical sense of $100 \%$ certainty, one is not even sure of the existence of the subjective feelings of one's spouse! Hence surely $99.99999999 \%$ is close enough to be taken as if $100 \%$ at the practical level. None of us worries about the $0.00 \ldots 1 \%$ possibility that our spouses or close friends do not really feel either. Practically the same goes for the feelings, and hence the welfare needs, of all mammals, if not all vertebrates, as established in the recent field of affective neuroscience (e.g., Mashour \& Alkire, 2013). If we go beyond virtual certainty $(99.9 \%+)$ to the level of almost certainty $(95 \%+)$, the range of animal species capable of feeling must be greatly widened, as even crayfish appear to be capable of anxiety (Fossat, 2014). (For informative and interesting accounts of the many impressive capabilities for feelings, including even moral feelings, of many animal species far beyond what we would have imagined, see e.g., Balcombe, 2010, and Bekoff, 2013.)

Dawkins (2014, p. 2) argues that "a seeming paradox at the heart of a science of animal welfare" is created by the world knot: "To be comprehensive enough to include what most people mean by animal welfare, it must involve understanding what animals consciously feel and experience. But to be a science, it has to embrace the one thing that biology currently finds very difficult, if not impossible to study, namely, animal consciousness." Dawkins discusses four ways out of this paradox: (1) denying the paradox by regarding animal consciousness as not a problem for scientific study; (2) doing the next best thing, by studying behavioral and physiological correlates of consciousness instead of studying consciousness directly; (3) believing that the paradox will disappear with more research; (4) regarding the resolution of the paradox as not central to a scientific study of animal welfare. As an eclectic, I believe that all four approaches contain some valid elements, but they are not enough to resolve the paradox fully. Instead of discussing the advantages and disadvantages of these four approaches in detail, I explain below how welfare biology $(\mathrm{Ng}, 1995)$ may help to resolve the paradox, or at least reduce its impact, and to provide useful guides on many issues of animal welfare.

In my welfare biology paper of 1995, I defined welfare biology as the study of living things with respect to their welfare, defined as net happiness (enjoyment minus suffering) and used evolutionary biology, population dynamics and economics to help answer three basic questions in welfare biology: (1) The individual members of which species are capable of suffering/enjoyment? (2) Are their welfare levels positive or negative? (3) How could their welfare be increased? These three questions of which, whether, and how somewhat parallel the three basic questions of economics: What, how, and for whom are the various goods and services produced? My basic training as an economist no doubt influenced my choice of the three basic welfare biological questions.

Owing to the difficulty of the world knot, the first question is very difficult to answer directly. However, using compelling axioms based on the principles of evolutionary biology, I show that a species must be flexible for its members to be capable of feeling. Roughly speaking, brain mechanisms giving rise to feelings must consume energy. If these feelings do not affect the flexible behavioral choices of the species, they do not contribute to their survival and reproductive fitness, and hence they cannot survive evolutionary competition. In evolutionary equilibrium, traits that are not adaptive are not retained. Thus, the behaviors of feeling species must be flexible, that is, not completely hard-wired genetically. 
This constraint transforms the first question about consciousness (which is very difficult to answer) into one about flexible behavior (still difficult but less so). If we can establish that the behavior of a species is completely inflexible, its members are unlikely capable of feeling. In contrast, species capable of flexible choices are likely to be capable of suffering/enjoyment.

This result obviously has important implications for the study of animal welfare. However, it has not been widely noticed during two decades since its publication. As I am not a biologist by training, I could develop the result only in its general terms. Further specific developments and applications call for more specific knowledge beyond my expertise. I hope that some biologists and those interested in animal welfare will be able to build further progress on my contributions.

Apart from the result about behavioral flexibility and feeling, my 1995 paper has several other implications that may be relevant for animal welfare. Generalizing the LotkaVolterra model of population dynamics, I showed that welfare can be increased without reducing the number of individual animals. This result was applied by Clarke and $\mathrm{Ng}(2006)$.

\section{Simple and Low-Cost Ways to Reduce Animal Suffering}

There are simple ways to reduce animal suffering substantially at a very low or zero cost or even a net gain - to humans. The following examples are just illustrative.

First, some simple regulations on the farming of animals can drastically reduce animal suffering. For example, in the factory farming of chickens, simple regulations on the minimum cage size can significantly improve chicken welfare. The inadequacy of current regulations and the inaction toward improving them are largely due to mistaken ideas. Most producers believe that stricter regulations will increase their costs and reduce their profits. However, since industries like factory chicken farming are highly competitive, they cannot generate long-run supernormal profits; they can only earn average rates of return. Thus, after a temporary period of adjustment, stricter regulations will only increase the prices of the final products without affecting the profitability of the producers. True, consumers will then have to pay higher prices. However, despite temporary setbacks due to the recent financial crisis, the longer-term trend is for more and more consumers to be willing to pay higher prices for products that involve less cruelty to animals (e.g., Grimsrud et al., 2013; Lagerkvist \& Hess, 2011; Miranda-de la Lama et al., 2013; Napolitano, 2010).

Moreover, at least for the developed economies, meat consumption is unhealthily excessive. Thus, the higher prices for meat, by inducing consumers to buy less meat, actually make them better off. The costs for humans of improving animal welfare may well be negative! This is not just wishful thinking, but it is supported by research. As shown by Gruber and Mullainathan (2005), taxes on cigarettes that increase their prices actually make smokers healthier and happier. An important role for animal welfare advocates would hence be to educate the public about this, showing how it would be to society's advantage to adopt stricter regulations on reducing animal suffering.

Second, the prohibition of cruelty to animals that serves no purpose at all should be extended. Just two examples are given here. First, as reported by Bekoff (2013, pp. 230-231) on the study of David Evans and Paul McGreevy (2011), "whipping horses [in horse racing] is pointless and does not make a difference in the outcome of the race ... increased whip use was not associated with significant variation in velocity." I would go further. Even if 
whipping were effective in increasing the speed, it should still be completely banned. Suppose whipping increased speed by $\mathrm{x} \%$. After banning, the speed of all horses would decrease by about $\mathrm{x} \%$. Since this applies to all horses in the race, it would not affect the competitive outcome. Problems such as unfairness would arise only if some horses were allowed to be whipped and some not. As banning should apply to all, no real problems are created, but we save much suffering for the horses.

As another example, fish mongers in the wet markets in Hong Kong (probably in other places as well) use the practice of cutting eels into two halves alive, leaving them wriggling in pain to attract customers and to show that their fish are very fresh. I have argued with them more than once that this would inflict pain. No one challenged me on this. However, one replied to me, "If I cannot sell the fish, I will also suffer pain!" Even assuming that the fish mongers are right in thinking that the practice helps them sell fish, it should still be banned. The pain of being cut into half and writhing in pain until death is too terrible to be tolerated. Moreover, forbidding a fish monger to do this only hurts him if others are allowed to continue to do it. If all fish mongers are prevented by law and enforcement from engaging in this cruel practice, they can still sell fish at the same rates.

As in the horse whipping example above, this is just another case of relative competition between individual producers or consumers that leads to inefficient social outcomes and a lot of needless suffering. Society needs to adopt legislative and lawenforcement measures to ban such inefficient competition that really serves no good purpose and causes so much gratuitous suffering. This should be distinguished from competition between producers in reducing costs or increasing the quality of products in a way that does increase efficiency. This efficient competition (that does not involve cruelty and other external costs like pollution) should be allowed if not encouraged. The problem is not competition as such but external costs to other sentients.

Third, we should put less emphasis on GDP (gross domestic product) and its growth and more on the environment and true welfare for both humans and other animals. Research in recent decades has shown that, above a relatively low threshold level, further increases in an individual's consumption do not really increase happiness significantly (as surveyed in Diener et al., 2010; Ng, 2015). This is even truer at the social level. Each individual may still find higher income and consumption important because of relative comparisons. However, at the social level, an increase in the relative standing of one implies decreases for others. On average, the relative income of the whole society cannot change. In addition, the production and consumption of most goods and services involve significant environmental disruption. Thus, even just from the human welfare point of view, we have excessive production and consumption. Income and consumption taxes, instead of being distortive (by distorting choices and hence imposing burdens on producers and consumers by an amount larger than the taxes collected) as most economists believe, are actually corrective (Ng, 2003). Moreover, economic growth may be (human) welfare-decreasing, even while ignoring the big destruction of the habitats of nonhuman animals. If we take account of animal welfare, even just weighting their relative importance at only $1 \%$, the desirability of environmentally unfriendly growth becomes very doubtful. When I proposed the environmentally responsible happy nation index $(\mathrm{Ng}, 2008)$ to supplement if not replace GDP, I took mainly human welfare into consideration. The additional consideration of animal welfare further strengthens the case for greater conservation and against environmental disruption. 
Environmental and animal welfare protection may be costly in reducing GDP produced. However, at least for most advanced economies, as higher consumption no longer increases happiness, the costs may only be large in monetary terms but trivial or even negative in true welfare terms. Money does not buy happiness, but since happiness also includes ultimate values, it may be that environmental and animal welfare protection is not really costly at all!

\section{Increasing the Influence of Animal Welfare Advocates}

This final section discusses some considerations that could be relevant to increasing the influence of animal welfare advocates.

First, we should be cautious not to exaggerate our claims in the hope of making them more convincing. For example, I find Bekoff's (2013) book very readable and informative, but I also find some of his conclusions somewhat hyperbolic. For example, the piece on "The Birds and the Bees and Their Brains: Size Doesn't Matter" presents evidence "that we need to be very careful making claims that invertebrates do not have emotional lives or feelings" (p. 153) because even small insect with tiny brains may be capable of much more feelings than we expect. So far this is fine. However, the conclusion that the size (of brains) doesn't matter is unwarranted. The evidence presented does not show that size does not matter, only that it is not the only thing that matters and that small size does not entail absence of feeling. The piece refers to Jerison's (1973) encephalization quotient: the positive proportionate excess of brain weight over $2 / 3$ of the body weight. The parameter of $2 / 3$ of the body weight is used because body surface area increases quadratically with proportionate increase in width, height, and length, whereas body weight increases cubically. The two-third increase in brain size is thus required simply to coordinate body senses and movement.

Jerison's data show clearly that this encephalization quotient shows a very clear positive correlation with intelligence. It cannot be concluded that size does not matter. It is true that intelligence is not feelings and that one does not have to be very intelligent to have strong feelings. It is also true that the matter of moral concern "is not a capacity to think, but a capacity to feel" (Balcombe, 2010, p. 44). However, the two are related (e.g., Keltner \& Horberg, 2015) and there is some correlation between a brain's size and complexity and its capability for both intelligence and feelings. The relevant brain structures and functions would seem to be the nociceptive ones, not just brute size, although brain size clearly matters as well. A brain of only a few neurons seems unlikely to be capable of either high intelligence or strong feelings.

Another example (quite common among biologists) of excessive claims is "All life has value and should be respected" (Bekoff, 2013, p. 309). In my view, it is not life as such that has value, but feeling (i.e., pleasures and pains in a wide sense, including spiritual and sensuous) that are of value (to the feeler). Values are felt values. If plants have no feelings, then, as non-feelers, they have no felt values of their own - though their lives may have high instrumental values for sustaining the lives of feeling animals.

Second, there are strategies that animal welfare advocates can use to increase their influence on behalf of feeling organisms without having to resort to hyperbole. One way is to focus efforts initially on measures that can increase animal welfare or reduce animal 
suffering enormously at small or even negative costs to humans, as discussed in the previous section, rather than on measures that are much more costly and likely to engender much more resistance. That way, acceptance and progress can be achieved more effectively.

Third, and related to the previous point, one consideration is the distinction between wild animals and farmed animals. Being much more numerous, wild animals are much more important in general and in the long term. However, as a near-term strategy, I suggest that, without ignoring wild animals altogether, our initial emphasis should be more on farmed animals, for a number of reasons. We are in more direct contact and directly responsible for their suffering. Hence, we are likely to gain converts more easily on this front. Also, for wild animals, we have less knowledge of them and have less influence over them (except for our encroachment on their traditional living habitats). Hence, our attempts to help them today may be less effective and less certain. Also, changes in the situation in the wild may have more long-term ecological repercussions. Hence, it may be wise to leave most measures on their behalf to the to the future, when we know more, after much more scientific progress, and after much greater concern for farmed animals has become the norm, legally and culturally.

Fourth, and related to the previous two points, we must recognize that we will be able to help animals more if and when our levels of scientific knowledge and technological and economic capabilities are much higher. Thus, while we should definitely do everything possible to reduce animal suffering where it is clearly unnecessary for either human or animal welfare, we should be careful in pressing for the curtailment of animal research that can increase our scientific knowledge in the interests of human or animal welfare. Impeding scientific advances could prove harmful not only to ourselves, but also to animals in the long run.

I view scientists using animals in their research as our potential collaborators rather than our enemies. We should of course persuade them to use the least painful means of experimentation possible. We should discourage and work to ban painful or stressful animal experimentation that serves no important purpose (e.g., to improve cosmetics, used for competition in attractiveness between individuals, which is mutually canceling at the social level, as discussed above). While we still desperately need advances in bioscience, human and veterinary medicine and technology, it makes far more sense for the initial focus of animal welfare advocates to be on reducing the enormous gratuitous suffering in factory farming. Even on this more limited scope of reducing suffering for farmed animals, we have so many things to work hard on.

In closing, my view on making an initial distinction between wild and farmed animal welfare, and on giving initial priority to reducing harm to animals when it is virtually costless and does not impede scientific advances, is just a starting position. Palpable progress with these relatively easier welfare problems will then serve as a foundation for extending our future efforts in eliminating all needless non-human and human animal suffering on the planet. 
Call for Commentary: Animal Sentience publishes Open Peer Commentary on all accepted target articles. Target articles are peer-reviewed. Commentaries are editorially reviewed. There are submitted commentaries as well as invited commentaries. Commentaries appear as soon as they have been revised and accepted. Target article authors may respond to their commentaries individually or in a joint response to multiple commentaries.

Instructions: http://animalstudiesrepository.org/animsent/guidelines.html

\section{References}

Balcombe, J. (2010). Second Nature. New York: Palgrave Macmillan.

Bekoff, M. (2013) Why Dogs Hump and Bees Get Depressed. New World Library.

Carpendale, M. (2013). Yew-Kwang Ng on Wild-Animal Suffering / Essays on Reducing Suffering. Essays on Reducing Suffering. http://reducing-suffering.org/yew-kwang-ngon-wild-animal-suffering/ (A revised version will be published in a special issue in Relations: Beyond Anthropocentrism, 2016.)

Chalmers, D. J. (1995). Facing up to the problem of consciousness. Journal of Consciousness Studies, 2(3), 200-219.

Clarke, M., \& Ng, Y-K. (2006). Population dynamics and animal welfare: Issues raised by the culling of kangaroos in Puckapunyal. Social Choice and Welfare, 27, 407-22.

Dawkins, M. (2014). Animal welfare and the paradox of animal consciousness. Advances in the Study of Behavior, 47, 1-34.

Dennett, D. C. (1991). Consciousness Explained. London: Penguin.

Diener, E., Helliwell, J., \& Kahneman, D. (2010). International Differences in Well-being. Oxford: Oxford University Press.

Evans, D., \& McGreevy, P. (2011). An investigation of racing performance and whip use by jockeys in thoroughbred races. Plos ONE, 6(1), e15622. http://dx.doi.org/10.1371/journal.pone.0015622

Fossat, P., Bacque-Cazenave, J., De Deurwaerdere, P., Delbecque, J., \& Cattaert, D. (2014). Anxiety-like behavior in crayfish is controlled by serotonin. Science, 344(6189), 12931297. http://dx.doi.org/10.1126/science.1248811

Grimsrud, K., Nielsen, H., Navrud, S., \& Olesen, I. (2013). Households' willingness-to-pay for improved fish welfare in breeding programs for farmed Atlantic salmon. Aquaculture, 372-375, 19-27. http://dx.doi.org/10.1016/j.aquaculture.2012.10.009 
Gruber, J., \& Mullainathan, S. (2005). Do cigarette taxes make smokers happier. Advances In Economic Analysis \& Policy, 5(1). http://dx.doi.org/10.2202/1538-0637.1412

Jerison, H. (1973). Evolution of the Brain and Intelligence. New York: Academic Press.

Keltner, D., \& Horberg, E. (2015). Emotion-cognition interactions. APA Handbook Of Personality And Social Psychology, Volume 1: Attitudes And Social Cognition, 623-664. http://dx.doi.org/10.1037/14341-020

Lagerkvist, C., \& Hess, S. (2010). A meta-analysis of consumer willingness to pay for farm animal welfare. European Review of Agricultural Economics, 38(1), 55-78. http://dx.doi.org/10.1093/erae/jbq043

Mashour, G., \& Alkire, M. (2013). Evolution of consciousness: Phylogeny, ontogeny, and emergence from general anesthesia. Proceedings Of The National Academy Of Sciences, 110 (Supplement 2), 10357-10364. http://dx.doi.org/10.1073/pnas.1301188110

Miranda-de la Lama, G., Sepúlveda, W., Villarroel, M., \& María, G. (2013). Attitudes of meat retailers to animal welfare in Spain. Meat Science, 95(3), 569-575.

http://dx.doi.org/10.1016/i.meatsci.2013.05.046

Napolitano, F., Girolami, A., \& Braghieri, A. (2010). Consumer liking and willingness to pay for high welfare animal-based products. Trends In Food Science \& Technology, 21(11), 537-543. http://dx.doi.org/10.1016/j.tifs.2010.07.01

Ng, Y-K. (1995). Towards welfare biology: Evolutionary economics of animal consciousness and suffering. Biology \& Philosophy, 10(3), 255-285.

http://dx.doi.org/10.1007/bf00852469

Ng, Y-K. (2003). From preference to happiness: Towards a more complete welfare economics. Social Choice And Welfare, 20(2), 307-350. http://dx.doi.org/10.1007/s003550200184

Ng, Y-K. (2008). Environmentally responsible happy nation index: Towards an internationally acceptable national success indicator. Social Indicators Research, 85(3), 425-446. http://dx.doi.org/10.1007/s11205-007-9135-1

Ng, Y-K. (2015). Happinessism. Taiwan: Wunan Press.

Ramachandran, V. (2012). The Tell-Tale Brain. London: Windmill.

Schopenhauer, A. (2014). The World as Will and Idea. Dobimick Publishing.

Walker, M., Diez-Leon, M., \& Mason, G. (2014). Animal welfare science: Recent publication trends and future research priorities. International Journal of Comparative Psychology, 27(1), 80-100. 
The Israel Journal of Ecology and Evolution is seeking manuscript submissions for a special edition on Compassionate Conservation. Guest editors are Drs. Dror Ben-Ami and Daniel Ramp. They are inviting original research that is exemplary of Compassionate Conservation values. Compassionate Conservation builds the welfare of individual wildlife into conservation practice to improve outcomes for individuals, species and ecosystems. It has four guiding principles: a commitment to doing no harm as a starting point for intervention, individuals matter, all wildlife are worthy of conservation, and peaceful coexistence should be the ultimate aim for conservation practice. Practical examples include non-lethal management of wildlife populations, including animal welfare in conservation solutions, non-invasive monitoring techniques for studying wildlife, and engagement of human communities to minimise human-wildlife conflict.

For more information please contact Daniel Ramp at Daniel.Ramp@uts.edu.au 